\title{
Ibrutinib as Treatment for Patients With Relapsed/Refractory Follicular Lymphoma: Results From the Open-Label, Multicenter, Phase II DAWN Study
} DOI:

$10.1200 / J C O .2017 .76 .8853$

\section{Document Version}

Final published version

Link to publication record in Manchester Research Explorer

Citation for published version (APA):

Gopal, A. K., Schuster, S. J., Fowler, N. H., Trotman, J., Hess, G., Hou, J-Z., Yacoub, A., Lill, M., Martin, P., Vitolo, U., Spencer, A., Radford, J., Jurczak, W., Morton, J., Caballero, D., Deshpande, S., Gartenberg, G. J., Wang, S-S., Damle, R. N., ... Salles, G. (2018). Ibrutinib as Treatment for Patients With Relapsed/Refractory Follicular Lymphoma: Results From the Open-Label, Multicenter, Phase II DAWN Study. J Clin Oncol, 36, 2405-2412. https://doi.org/10.1200/JCO.2017.76.8853

\section{Published in:}

$\mathrm{J}$ Clin Oncol

\section{Citing this paper}

Please note that where the full-text provided on Manchester Research Explorer is the Author Accepted Manuscript or Proof version this may differ from the final Published version. If citing, it is advised that you check and use the publisher's definitive version.

\section{General rights}

Copyright and moral rights for the publications made accessible in the Research Explorer are retained by the authors and/or other copyright owners and it is a condition of accessing publications that users recognise and abide by the legal requirements associated with these rights.

\section{Takedown policy}

If you believe that this document breaches copyright please refer to the University of Manchester's Takedown Procedures [http://man.ac.uk/04Y6Bo] or contact uml.scholarlycommunications@manchester.ac.uk providing relevant details, so we can investigate your claim.

\section{OPEN ACCESS}


Author affiliations and support information (if applicable) appear at the end of this article.

Published at jco.org on May 31, 2018. Clinical trial information: NCT01779791.

Corresponding author: Ajay K. Gopal, MD, Seattle Cancer Care Alliance, 825 Eastlake Ave E \#G3200, Seattle, WA 98109; e-mail: agopal@u.washington.edu.

(C) 2018 by American Society of Clinical Oncology

$0732-183 X / 18 / 3623 w-2405 w / \$ 20.00$

\section{Ibrutinib as Treatment for Patients With Relapsed/Refractory Follicular Lymphoma: Results From the Open-Label, Multicenter, Phase II DAWN Study}

Ajay K. Gopal, Stephen J. Schuster, Nathan H. Fowler, Judith Trotman, Georg Hess, Jing-Zhou Hou, Abdulraheem Yacoub, Michael Lill, Peter Martin, Umberto Vitolo, Andrew Spencer, John Radford, Wojciech Jurczak, James Morton, Dolores Caballero, Sanjay Deshpande, Gary J. Gartenberg, Shean-Sheng Wang, Rajendra N. Damle, Michael Schaffer, Sriram Balasubramanian, Jessica Vermeulen, Bruce D. Cheson, and Gilles Salles

\section{$\begin{array}{llllllll}\text { A } & \text { B } & \mathbf{S} & \mathbf{T} & \mathbf{R} & \mathbf{A} & \mathbf{C} & \mathbf{T}\end{array}$}

\section{Purpose}

The Bruton's tyrosine kinase inhibitor ibrutinib has demonstrated clinical activity in B-cell malignancies. The DAWN study assessed the efficacy and safety of single-agent ibrutinib in chemoimmunotherapy relapsed/refractory follicular lymphoma (FL) patients.

\section{Methods}

DAWN was an open-label, single-arm, phase II study of ibrutinib in patients with FL with two or more prior lines of therapy. Patients received ibrutinib $560 \mathrm{mg}$ daily until progressive disease/unacceptable toxicity. The primary objective was independent review committee-assessed overall response rate (ORR; complete response plus partial response). Exploratory analyses of T-cell subsets in peripheral blood (baseline/cycle 3) and cytokines/chemokines (baseline/cycle 2) were performed for available samples.

\section{Results}

Between March 2013 and May 2016, 110 patients with a median of three prior lines of therapy were enrolled. At median follow-up of 27.7 months, ORR was $20.9 \%$ (95\% Cl, 13.7\% to 29.7\%, which did not meet the $18 \%$ lower-bound threshold for the primary end point). Twelve patients achieved a complete response $(11 \% ; 95 \% \mathrm{Cl}, 5.8 \%$ to $18.3 \%)$. Median duration of response was 19.4 months (range, 1 to $\geq 33$ months), with a median progression-free survival of 4.6 months and a 30-month overall survival of $61 \%(95 \% \mathrm{Cl}, 0.51 \%$ to $0.70 \%)$. Lymphoma symptoms resolved in $67 \%$. Seven of 32 patients who experienced initial radiologic progression responded upon continuing therapy (pseudoprogression). The most common adverse events were diarrhea, fatigue, cough, and muscle spasms; $48.2 \%$ of patients reported serious adverse events. In patients who experienced a response, regulatory T cells were downregulated at C3D1 $(P=.02)$, and Th1-promoting (antitumor) cytokines interferon- $\gamma$ and interleukin-12 increased $(P \leq .035)$.

\section{Conclusion}

With an ORR of $20.9 \%$, ibrutinib failed to meet its primary efficacy end point in chemoimmunotherapy in patients with relapsed/refractory $F L$, although responses were durable and associated with a reduction in regulatory $T$ cells and increases in proinflammatory cytokines.

\section{J Clin Oncol 36:2405-2412. () 2018 by American Society of Clinical Oncology}

\section{INTRODUCTION}

Follicular lymphoma (FL) is the second most common non-Hodgkin lymphoma, comprising $17 \%$ to $22 \%$ of cases. ${ }^{1,2}$ Most patients who are diagnosed with FL initially receive chemoimmunotherapy (CIT) or rituximab ${ }^{3}$; however, despite good initial responses to CIT, FL is incurable in most patients and relapse generally occurs, ${ }^{4}$ with poor outcomes after early relapse or CIT-resistant disease. ${ }^{5}$

Therapies that target B-cell receptor (BCR) pathway components, such as spleen tyrosine kinase, phosphatidylinositol 3-kinase, and Bruton's tyrosine kinase (BTK), which are involved in various B-cell malignancies, are being developed. ${ }^{6}$ Ibrutinib (Imbruvica; Pharmacyclics, Sunnyvale, CA, and Janssen Biotech, Horsham, PA) covalently binds cysteine 481 on the BTK enzyme and 
has demonstrated clinical activity in B-cell malignancies, including chronic lymphocytic leukemia (CLL), Waldenström macroglobulinemia, mantle-cell lymphoma, and marginal-zone lymphoma. ${ }^{7,8}$ Preliminary data indicate that ibrutinib can yield response rates that range from $25 \%$ to $63 \%$ in patients with relapsed FL. ${ }^{9-11}$

Data also exist that suggest that the tumor microenvironment may contribute to the development and progression of FL, and the interaction of FL cells with immune cells in the tumor may influence the clinical course and response to therapy. ${ }^{12,13}$ Ibrutinib seems to exert immunomodulatory effects on T-cell activity via the inhibition of interleukin-2 (IL-2) -inducible T-cell kinase (ITK), a key regulator of T-cell activity, possibly through the inhibition of T-helper 2 (Th2) -polarized CD4 T cells and activation of Th1 cells. ${ }^{14}$ Interferon- $\gamma$ (IFN- $\gamma$ )-secreting Th1type cells are thought to promote antitumor cellular immunity, whereas Th2-type cells may lead to immune suppression and tumor evasion. ${ }^{15}$

On the basis of the safety and efficacy of ibrutinib in other B-cell malignancies, preliminary data in FL, and the potential additional immune mechanism of action of ibrutinib, we conducted this pivotal trial of ibrutinib in patients with CIT-resistant FL.

\section{METHODS}

\section{Patients}

This study enrolled patients age 18 years or older with a diagnosis of grade 1,2 , or 3 a nontransformed FL who had been treated with two or more prior lines of therapy and were refractory or had experienced relapse on the last prior line of therapy with an anti-CD20 monoclonal antibodycontaining CIT regimen. Full inclusion and exclusion criteria are presented in the Data Supplement. Patients who did not meet inclusion/exclusion criteria were not enrolled.

The study was conducted in accordance with International Conference on Harmonisation Good Clinical Practice guidelines and was approved by an independent institutional review board. All patients provided written informed consent.

\section{Study Design}

This open-label, multicenter, single-arm, phase II study of ibrutinib enrolled patients with CIT-relapsed/refractory FL across 45 centers in 10 countries.

An overview of the study design is presented in the Data Supplement. Eligible patients received ibrutinib $560 \mathrm{mg}$-four 140-mg capsules-orally once per day until disease progression or unacceptable toxicity. For the first toxicity event (absolute neutrophil count $<500 / \mathrm{mm}^{3}$; platelets $<25,000 / \mathrm{mm}^{3}$; platelets $<50,000 / \mathrm{mm}^{3}$ with grade $\geq 2$ bleeding; grade 3 or 4 nausea, vomiting, or diarrhea; grade 4 toxicities; or unmanageable grade 3 drugrelated toxicities), ibrutinib treatment was suspended until recovery to grade 1 or less or baseline ( $\leq 21$ consecutive days), then resumed. For the second and third occurrence, ibrutinib was suspended until recovery, then resumed at a lower dose $(420 \mathrm{mg}$ and $280 \mathrm{mg}$ per day for the second and third events, respectively). Ibrutinib was discontinued if an event occurred a fourth time.

Concomitant administration of hematopoietic growth factors and supportive care therapies was permitted. To allow for the possibility of including patients who exhibited tumor flare (pseudo-progressive disease [PD]) and delayed responses, the protocol was amended in January 2014 to enable patients with radiologic evidence of PD who were clinically stable or improving or who had signs of tumor flare without confirmation of PD by positron emission tomography (PET) or biopsy to remain on ibrutinib upon investigator request and sponsor approval. ${ }^{16}$

\section{Study Assessments and End Points}

Efficacy evaluations included computed tomography scans; magnetic resonance imaging; ${ }^{18} \mathrm{~F}$-labeled fluorodeoxyglucose PET; bone marrow biopsy; physical assessment, including lymphoma-B symptoms; and Eastern Cooperative Oncology Group performance status. Lymphomarelated B symptoms and other lymphoma-related symptoms were assessed at baseline and at each visit. Disease evaluations were performed at screening, every 12 weeks ( \pm 7 days) for 96 weeks, then every 24 weeks $( \pm 14$ days) until disease progression or 24 months after the last patient was enrolled.

The primary end point of the study was the overall response rate (ORR; complete response [CR] plus partial response [PR]) as assessed by an independent review committee, determined using standard criteria. ${ }^{17}$ Patients with confirmed response after pseudo-PD were considered responders and were included in the ORR. Date of progression for patients who continued therapy after PD and did not later have a confirmed response was that of initial PD. Duration of response (DOR), time to response, progression-free survival (PFS), overall survival (OS), time to next therapy (TTNT), and resolution of lymphoma-related symptoms were included as secondary end points. Biomarkers were an exploratory analysis. All biomarker assessments and clinical laboratory tests were analyzed by a central laboratory. Data to describe the safety profile were collected.

\section{Statistical Methods}

Sample size was determined to achieve $>85 \%$ power to declare the lower bound of the $95 \%$ CI of the ORR to exceed $18 \%$, assuming an ORR of $30 \%$ for ibrutinib treatment. The all-treated population that was evaluated for primary efficacy and safety included all patients who received at least one dose of the study medication. Patients were described as refractory to the previous line of therapy if they experienced a failure to achieve at least PR to the prior line of therapy or as relapsed if they experienced disease progression $\leq 12$ months after achieving response with the prior regimen.

OS and PFS were analyzed in the all-treated population, and patients who experienced events after the start of subsequent therapy or those with no event at the clinical cutoff were censored to the last assessment before subsequent therapy. Response distribution was evaluated using the KaplanMeier method. Sensitivity analyses were performed using investigator assessment without censoring at subsequent therapy if initiated before disease progression. For time to response and resolution of lymphomarelated B symptoms, descriptive summaries are presented. Statistical analyses were performed using SAS (SAS/STAT User's Guide, Version 9.1; SAS Institute, Cary, $\mathrm{NC}$ ).

\section{Biomarker Analyses}

T-cell subsets in peripheral blood were assessed via flow cytometry at baseline (cycle 1, day 1) and at cycle 3, day 1 (markers included in the Data Supplement). Cytokine/chemokine analysis was performed at cycle 1, day 1 and at cycle 2, day 1 using the SomaLogic SOMAscan Assay (Boulder, CO). Differences in biomarkers between responder subgroups were compared via post hoc analysis using Wilcoxon rank sum test.

\section{RESULTS}

\section{Patient Characteristics}

Between March 2013 and May 2016, 110 patients who received at least one dose of ibrutinib were included in the analysis (Data Supplement). Patient baseline demographic and disease characteristics are listed in Table 1. Median age was 61.5 years (range, 28 to 87 years), and the majority of patients were male $(61 \%)$. A total of $64(58 \%)$ of 110 patients had a high (three or 


\begin{tabular}{|c|c|}
\hline Demographic or Characteristic & All Treated $(N=110)$ \\
\hline Median age (range), years & $61.5(28.0-87.0)$ \\
\hline Male sex & $67.0(60.9)$ \\
\hline \multicolumn{2}{|l|}{ ECOG performance status } \\
\hline 0 & $55.0(50.0)$ \\
\hline 1 & $55.0(50.0)$ \\
\hline \multicolumn{2}{|l|}{ FL stage } \\
\hline I & $4.0(3.6)$ \\
\hline II & $14.0(12.7)$ \\
\hline III & $32.0(29.1)$ \\
\hline IV & $60.0(54.5)$ \\
\hline \multicolumn{2}{|l|}{ FLIPI score } \\
\hline 0-1 & $21.0(19.1)$ \\
\hline 2 & $25.0(22.7)$ \\
\hline $3-5$ & $64.0(58.2)$ \\
\hline Largest tumor $\leq 6 \mathrm{~cm}$ & $89.0(80.9)$ \\
\hline Median (range) prior lines of therapy & $3.0(2.0-13.0)$ \\
\hline LDH $>$ upper limit of normal & $49.0(44.5)$ \\
\hline $\begin{array}{l}\text { Relapsed within } 12 \text { months of prior line of } \\
\text { therapy after PR or better }\end{array}$ & $65.0(59.1)$ \\
\hline $\begin{array}{l}\text { Prior regimen to which patients were refractory* } \\
\quad \text { or relapsed within } 6 \text { months }\end{array}$ & $45.0(40.9)$ \\
\hline Rituximab & $94.0(85.5)$ \\
\hline Alkylating agent & $63.0(57.3)$ \\
\hline Both & $63.0(57.3)$ \\
\hline \multicolumn{2}{|c|}{$\begin{array}{l}\text { NOTE. Data presented as No. (\%) unless otherwise indicated. } \\
\text { Abbreviations: ECOG, Eastern Cooperative Oncology Group; FL, follicular } \\
\text { lymphoma; FLIPI, Follicular Lymphoma International Prognostic Index; PR, partial } \\
\text { response. } \\
\text { *Refractory disease was defined as a failure to achieve at least a partial re- } \\
\text { sponse to the last regimen before study entry. }\end{array}$} \\
\hline
\end{tabular}

more risk factors) FL international prognostic index score. ${ }^{18} \mathrm{~Pa}$ tients had received a median of three (range, two to 13) prior lines of therapy, and 59\% had experienced relapse (relapse/disease progression within 12 months after achieving at least a PR), whereas $41 \%$ of patients were refractory to the prior line of therapy, which was defined as having experienced a failure to achieve at least a PR to the last prior treatment. For the last prior line of therapy, median TTNT was 10.0 months (95\% CI, 8.6 to 11.6 months), median PFS was 7.4 months (95\% CI, 6.3 to 8.6 months), and $85 \%$ of patients (94 of 110) experienced relapse or progression within 6 months. Patients were observed for a median of 27.7 months (range, 1.1 to 37.1 months). Patient disposition is presented in Table 2.

\section{Patient Outcomes}

Overall, 23 of 110 patients experienced a response to ibrutinib treatment, with an ORR of $20.9 \%$ (95\% CI, $13.7 \%$ to $29.7 \%$ ), of which 12 patients $(11 \%$; $95 \%$ CI, $5.8 \%$ to $18.3 \%)$ had a CR. The study did not meet its primary objective, predefined as an ORR with the lower bound of the $95 \%$ CI of $>18 \%$. Median time to initial response was 5.7 months (range, 2.6 to 13.8 months) with a median DOR of 19.4 months (range, 1 to $\geq 33$ months), and $33 \%$ (36 of 110) of patients experienced stable disease (SD) or better for $\geq 6$ months. Figure 1A illustrates the $66 \%$ of patients with a reduction in target tumor size. ORR was identical when assessed via PET versus computed tomography scan.

A descriptive subgroup analysis demonstrated that ORR did not differ substantially across age, sex, race, geographic region, prior lines of therapy, baseline Eastern Cooperative Oncology
Group performance status, baseline FL histology grade, lymphoma symptoms at baseline, and prior bendamustine treatment, with the exception of patients with bulk $>6-\mathrm{cm}$ or extranodal disease (Data Supplement). A post hoc analysis determined an ORR of $21 \%$ (20 of 94) among patients who had not achieved a response or who had experienced progression within 6 months of prior CIT. In addition, ORRs for patients who were refractory to rituximab and/or alkylator therapy were similar to that of the overall study population.

To account for the possibility of tumor flare or delayed response, 32 patients without clinical signs of progression were permitted to continue receiving ibrutinib after initial radiographic evidence of disease progression. Among these patients, seven (23\%) had independent review committee-confirmed responsefour CR and three PR - after remaining on therapy at a median of 22.0 weeks (range, 11.6 to 59.6 weeks) after starting ibrutinib. Of seven patients with pseudo-PD, three-two CR and one $\mathrm{PR}$ - patients maintained their response for $>1$ year and two have continued to respond for $>27$ months.

Median TTNT was 16.0 months (95\% CI, 10.7 to 19.1 months), and 2 years after initiating ibrutinib treatment, 34\% (95\% CI, 0.25\% to $0.44 \%$ ) of patients did not require subsequent anticancer therapy. Median PFS was 4.6 months (95\% CI, 2.8 to 5.5 months; Fig 1B), with a PFS rate at 30 months of $11 \%(95 \% \mathrm{CI}, 0.05 \%$ to $0.18 \%)$. Median OS was not reached after 27.7 months of follow-up (Fig 1C). The 12 -month OS was $78 \%$ (95\% CI, $0.69 \%$ to $0.85 \%$ ), whereas the 30 -month OS was $61 \%$ ( $95 \% \mathrm{CI}, 0.51 \%$ to $0.70 \%)$.

Among 39 patients with lymphoma-related symptoms at baseline, resolution of symptoms was observed in two thirds of patients (26 patients [67\%]), with a median time to resolution of 0.7 months (95\% CI, 0.7 to 1.4 months). Symptom resolution lasted a median of 10.4 months (95\% CI, 6.5 months to not estimable). Eight patients achieved a clinical response of PR or better (five CR and three PR, including three with pseudo-PD), 10 had SD, and eight had PD.

\section{Biomarker Analyses}

Data on T-cell subsets were obtained from $14(61 \%)$ of 23 patients who achieved a response (CR + PR) and $43(49 \%)$ of

\begin{tabular}{|c|c|}
\hline Patient Status & $\begin{array}{l}\text { Ibrutinib } \\
(\mathrm{N}=110)\end{array}$ \\
\hline Median treatment duration (range), months & $7.0(1.0-37.0)$ \\
\hline Median duration of follow up (range), months & $27.7(1.1-37.1)$ \\
\hline $\begin{array}{l}\text { Patients with prescribed dose reductions } \\
\text { Reason for dose reduction }\end{array}$ & $1.0(0.9)$ \\
\hline Neutropenia & $1.0(0.9)$ \\
\hline \multicolumn{2}{|l|}{ Study treatment phase disposition } \\
\hline \multicolumn{2}{|l|}{ Primary reason for discontinuation } \\
\hline Progressive disease or relapse & $72.0(65.5)$ \\
\hline $\begin{array}{l}\text { Rolled into long-term extension study } \\
\text { (NCT01804686) }\end{array}$ & $13.0(11.8)$ \\
\hline Physician decision & $10.0(9.1)$ \\
\hline Death & $4.0(3.6)$ \\
\hline Lost to follow-up & $1.0(0.9)$ \\
\hline Adverse event & $7.0(6.4)$ \\
\hline Withdrawal of consent & $3.0(2.7)$ \\
\hline
\end{tabular}




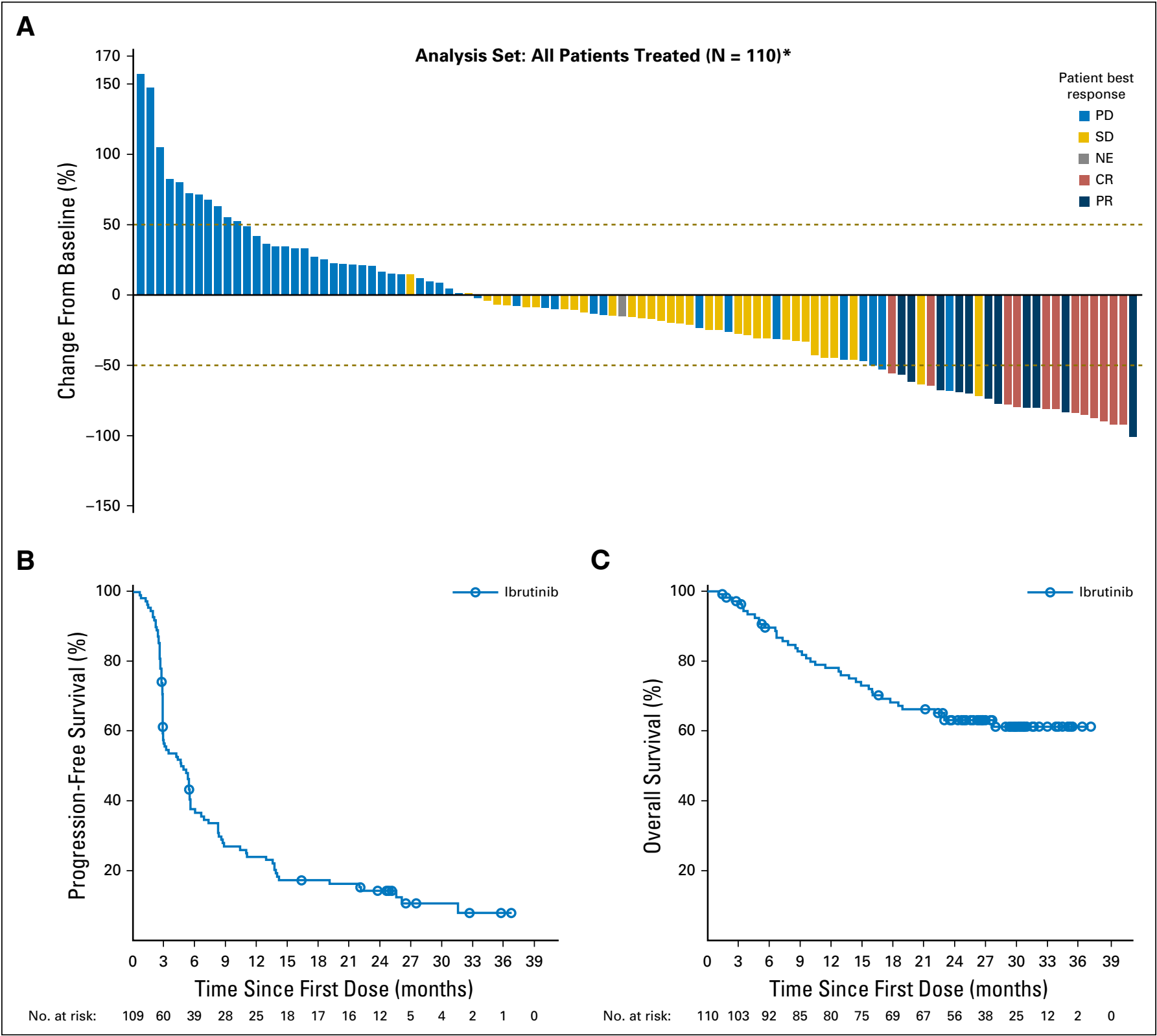

Fig 1. (A) Percent change in tumor size, and Kaplan-Meier curves for (B) progression-free survival and (C) overall survival. CR, complete response; NE, not estimable; PD, progressive disease; PR, partial response; SD, stable disease. $\left(^{*}\right)$ Patients in the independent review committee-assessed, all-treated population with both baseline and at least one postbaseline tumor measurement were included.

87 patients who did not achieve a response (SD + PD). T-cell subset analysis revealed significant downregulation of CD4 ${ }^{+} \mathrm{CD} 25^{+} \mathrm{CD}_{127}{ }^{-}$regulatory $\mathrm{T}$-cells $\left(\mathrm{T}_{\text {regs }}\right)$ at cycle 3 , day 1 in responders (mean decrease from $17 \%$ to $13 \%$ of CD4; $P=.02$ ), but not in nonresponders ( $12 \%$ to $10 \%$ of CD4; $P=.17$; Fig $2 \mathrm{~A})$. Cytokine analyses performed on samples from $21(91 \%)$ of 23 responders and $29(33 \%)$ of 87 nonresponders found that Th1-promoting cytokines IFN- $\gamma$ and IL-12 were significantly increased in responders but not in nonresponders (Fig 2B). Specifically, IFN- $\gamma$ demonstrated a mean increase of $19 \%$ in responders versus an $18 \%$ decrease in nonresponders at cycle 2 , day $1(P=.0025)$, whereas IL-12 had a mean increase of $7 \%$ in responders and a decrease of $6 \%$ in nonresponders $(P=.035)$.
IL-10 demonstrated an increase of $4 \%$ in nonresponders versus a decrease of $3 \%$ in responders $(P=.077)$. IL-4 had a mean increase of $15 \%$ in responders versus a decrease of $8 \%$ in nonresponders $(P=.016)$. Significant changes in inflammatory chemokines included decreases of $13 \%$ and $11 \%$ in IFN- $\gamma$ inducible protein $10 \mathrm{kDa}$ (IP-10) and monocyte chemotactic protein 3 (MCP-3), respectively, in responders versus increases of $42 \%$ and $11 \%$, respectively, in nonresponders $(P=.021$ and .016 , respectively). In samples that were available from six patients with pseudo-PD, IFN- $\gamma$ and IL-10 changes at cycle 2 , day 1 tended to resemble those in nonresponders, whereas changes in IP-10 and MCP-3 were similar to those observed in responders (Table 3). 


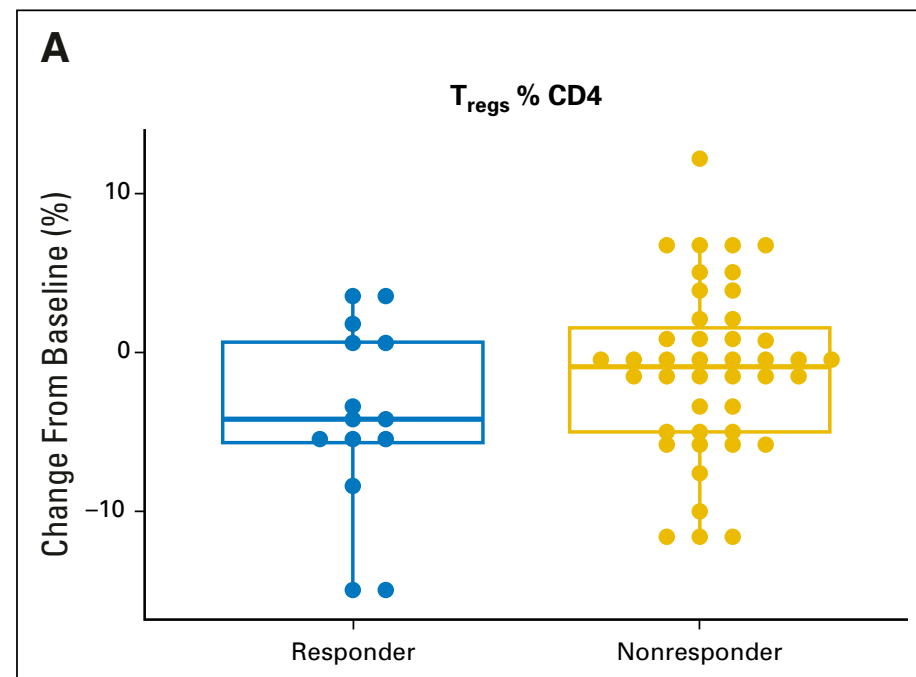

B

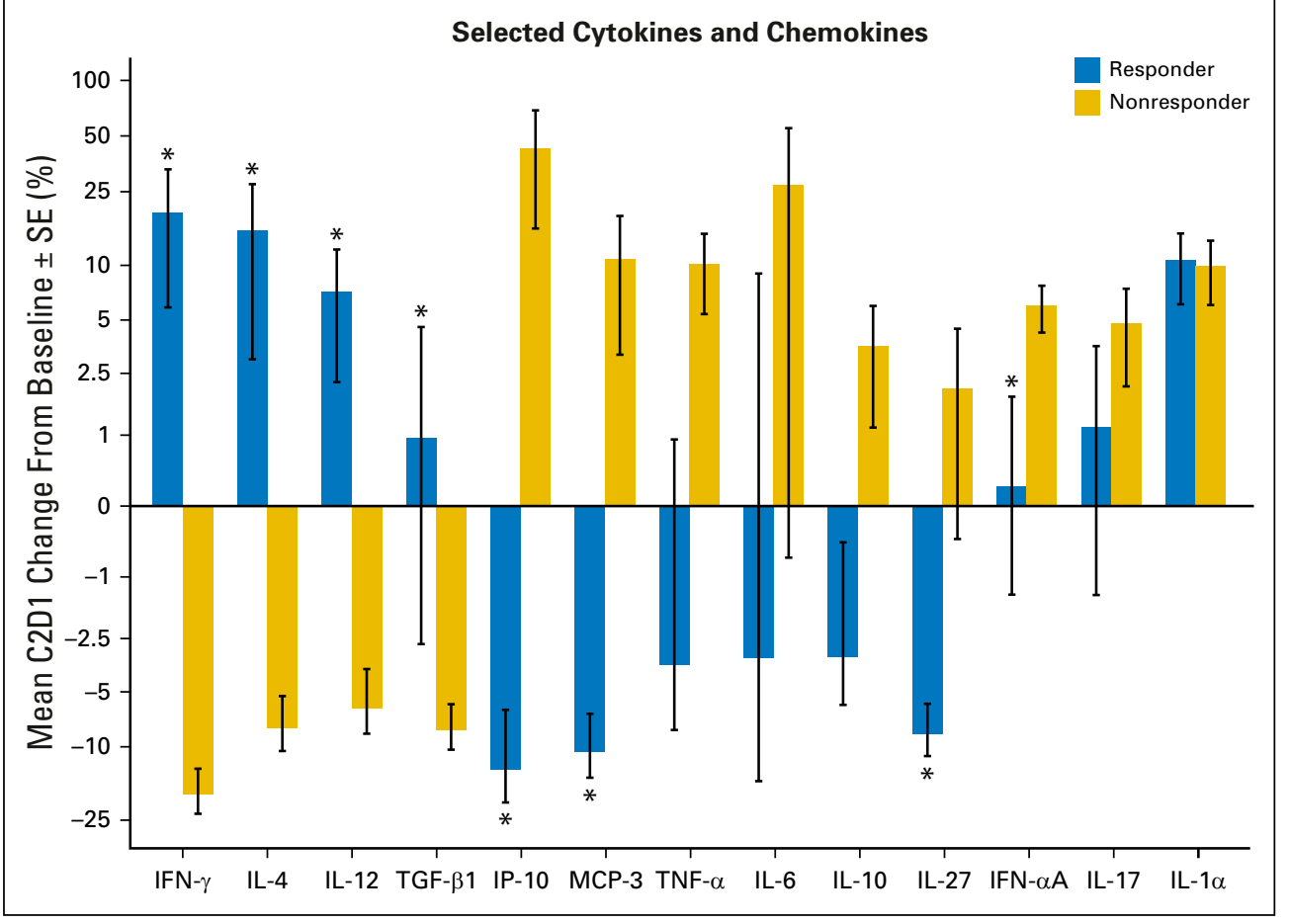

Fig 2. Changes in (A) $\mathrm{CD} 4^{+} \mathrm{CD} 25^{+} \mathrm{CD} 127^{-}$ regulatory $T$ cells $\left(T_{\text {regs }}\right)$ and $(B)$ cytokines among responders and nonresponders. C2D1, cycle 2, day 1; IFN, interferon; IL, interleukin; IP, interferon- $\boldsymbol{\gamma}$-induced protein; MCP, monocyte chemotactic protein; TGF, tumor growth factor.

\section{Treatment Exposure and Safety}

Ibrutinib treatment was continued for a median duration of 7.0 months (range, 1 to 37 months) at a mean daily dose of $539 \mathrm{mg}$ (standard deviation, $40.6 \mathrm{mg}$ ). Treatment-emergent adverse events were reported in 107 patients (97\%), and the most commonly reported adverse events (AEs; $\geq 10 \%$ of patients) are summarized in Table 4. Grade 3 or worse AEs occurred in 68 patients (62\%; Data Supplement). AEs that occurred in $\geq 5 \%$ of patients are presented by toxicity grade in the Data Supplement.

Seven patients (6\%) reported AEs as the primary reason of discontinuation, with subdural hematoma that led to discontinuation in two patients $(2 \%)$. One patient required a dose reduction as a result of neutropenia.
Serious AEs were reported in 53 patients (48\%), the most common ( $\geq 2 \%$ of patients) of which were pneumonia and pyrexia (seven patients each $[6 \%]$ ), pleural effusion (four patients [4\%]), and sepsis, atrial fibrillation (AF), and diarrhea (three patients each $[3 \%]$ ). Eight patients (7\%) died during the study, including three deaths as a result of AEs either during treatment or within 30 days of the last dose of the study drug. The two cases of AEs that led to death that were possibly related to ibrutinib were neutropenic sepsis and pneumonia; death unrelated to ibrutinib was because of embolism. AEs of special interest included major hemorrhage in four patients (4\%), and one patient (1\%) each reported subdural hematoma and cerebral hemorrhage, subdural hematoma after a head injury, an infected hematoma, and postprocedural hemorrhage. Grade $\geq 3$ infections and infestations occurred in 


\begin{tabular}{|c|c|c|c|}
\hline Cytokine & $\begin{array}{l}\text { Responders } \\
\qquad(\mathrm{n}=21)\end{array}$ & $\begin{array}{l}\text { Nonresponders } \\
\quad(\mathrm{n}=29)\end{array}$ & $\begin{array}{c}\text { Pseudo-PD } \\
\text { Patients } \\
(n=6)\end{array}$ \\
\hline IFN- $\gamma$ & $\begin{array}{l}19.4(61.8) \\
P=.002\end{array}$ & $-18.1(26.6)$ & $-19.7(17.5)$ \\
\hline IL-4 & $\begin{array}{l}15.2(55.7) \\
P=.016\end{array}$ & $-7.9(14.1)$ & $31.3(103.0)$ \\
\hline IL-12 & $\begin{array}{l}7.2(22.5) \\
P=.035\end{array}$ & $-6.1(12.8)$ & 0.7 (30.5) \\
\hline TGF- $\beta 1$ & $\begin{array}{l}1.0(16.7) \\
P=.046\end{array}$ & $-8.1(12.0)$ & $-11.7(11.7)$ \\
\hline IP-10 & $\begin{array}{c}-13.1(31.4) \\
P=.022\end{array}$ & $42.2(142)$ & $-17.3(31.2)$ \\
\hline MCP-3 & $\begin{array}{c}-10.6(18.5) \\
P=.016\end{array}$ & $10.8(40.7)$ & $-10.6(23.5)$ \\
\hline TNF- $\alpha$ & $\begin{array}{l}-3.6(20.6) \\
P=.099\end{array}$ & $10.0(25.1)$ & $11.2(7.0)$ \\
\hline IL-6 & $\begin{array}{l}-3.2(55.7) \\
P=.640\end{array}$ & $27.1(150.0)$ & 20.8 (85.6) \\
\hline IL-10 & $\begin{array}{l}-3.2(12.4) \\
P=.077\end{array}$ & $3.6(13.1)$ & $4.0(13.1)$ \\
\hline IL-27 & $\begin{array}{l}-8.5(12.2) \\
P=.007\end{array}$ & $2.0(13.2)$ & $-10.1(18.5)$ \\
\hline IFN- $\alpha \mathrm{A}$ & $\begin{array}{c}0.2(7.2) \\
P=.017\end{array}$ & $6.0(9.2)$ & $4.7(8.1)$ \\
\hline IL-17 & $\begin{array}{l}1.1(11.3) \\
P=.495\end{array}$ & $4.8(14.2)$ & $9.5(4.5)$ \\
\hline IL-1 $\alpha$ & $\begin{array}{l}10.5(20.0) \\
P=.969\end{array}$ & 9.8 (19.9) & $20.1(26.0)$ \\
\hline \multicolumn{4}{|c|}{$\begin{array}{l}\text { NOTE. Data are given as mean percent change (standard deviation), unless } \\
\text { otherwise noted. } \\
\text { Abbreviations: IFN, interferon; IL, interleukin; IP, interferon- } \gamma \text {-induced protein } \\
\text { MCP, monocyte chemotactic protein; PD, progressive disease; TGF, tumor } \\
\text { growth factor. }\end{array}$} \\
\hline
\end{tabular}

25 patients $(23 \%)$. AF occurred in 10 patients (9\%), of which four (4\%) were grade $\geq 3$. Tumor lysis syndrome was reported in one patient $(1 \%)$.

\section{DISCUSSION}

Here, we show that single-agent ibrutinib produced a response in approximately $21 \%$ of patients with CIT relapsed/refractory FL. Whereas the study did not achieve its primary objective and the data from this trial are less impressive compared with results observed using ibrutinib for the treatment of CLL, marginal-zone lymphoma, and mantle-cell lymphoma, ${ }^{19-23}$ secondary end points, such as a median DOR of 19.4 months, a disease control rate (ORR + SD for $\geq 6$ months) of $33 \%$, and a lymphoma symptom resolution rate of $67 \%$ suggest benefits of this therapy in some patients. Preclinical data have demonstrated that the phosphorylation of BCR signaling nodes and sensitivity to $\alpha$-BCR vary dramatically between B-cell lymphoma subtypes, and these findings are associated with sensitivity to BTK-mediated killing. ${ }^{24}$ Specifically, a subset of tumor cells within FL has been shown to demonstrate an absence of BCR signaling and resistance to agents that target the BCR signaling pathway. ${ }^{25}$ This BCR-resistant clone seems to increase after chemotherapy, potentially explaining the modest efficacy we observed in our trial of patients who were precisely selected on the basis of CIT resistance. These data may also imply that less heavily pretreated FL that contains a greater fraction of tumor cells with active BCR signaling could demonstrate increased sensitivity to ibrutinib.

Ibrutinib treatment tolerability was consistent with previous studies, with $6 \%$ of patients discontinuing as a result of toxicity and only one patient requiring dose reduction. Recommendations for patient monitoring and dose adjustments for AEs in the protocol were consistent with US prescribing information, and, given the lack of any new safety signals in this study, no additional considerations emerged for patients with FL treated with ibrutinib. ${ }^{7}$ As in previously reported studies of ibrutinib, ${ }^{22}$ the majority of AEs was grade 1 and 2, and comparable rates of AF were observed.

We also investigated potential biomarkers at baseline and early in treatment to better understand the potential biologic effect of ibrutinib in FL. No baseline markers that were predictive for response could be identified. Downregulation of $\mathrm{T}_{\text {regs }}$ after the start of ibrutinib therapy was observed only in patients who achieved a response, which is consistent with previous reports of ibrutinib treatment in patients with CLL that resulted in the downregulation of $\mathrm{T}_{\text {regs }}$ and a reduction of immune checkpoint protein programmed death-1 expression, which may promote the recovery of normal immune function. ${ }^{26,27}$

Ibrutinib may exert these immunomodulatory effects and prevent tumor-promoting signaling from the microenvironment via inhibition of ITK, a key regulator of T-cell activity. Ibrutinib has

\begin{tabular}{|c|c|c|c|}
\hline \multirow[b]{2}{*}{ Adverse Event, No. (\%) } & \multicolumn{3}{|c|}{$\begin{array}{l}\text { Safety Analysis Population } \\
\qquad(\mathrm{N}=110)\end{array}$} \\
\hline & Grade 1 and 2 & Grade 3 and 4 & Grade 5 \\
\hline Diarrhea & $51.0(46.4)$ & $5.0(4.5)$ & 0.0 \\
\hline Fatigue & $38.0(34.5)$ & $6.0(5.5)$ & 0.0 \\
\hline Cough & $39.0(35.5)$ & 0.0 & 0.0 \\
\hline Muscle spasms & $35.0(31.8)$ & 0.0 & 0.0 \\
\hline Nausea & $31.0(28.2)$ & $1.0(0.9)$ & 0.0 \\
\hline Peripheral edema & $30.0(27.3)$ & $1.0(0.9)$ & 0.0 \\
\hline Pyrexia & $25.0(22.7)$ & $2.0(1.8)$ & 0.0 \\
\hline Anemia & $15.0(13.6)$ & $10.0(9.1)$ & 0.0 \\
\hline Thrombocytopenia & $16.0(14.5)$ & $5.0(4.5)$ & 0.0 \\
\hline Headache & $18.0(16.4)$ & $1.0(0.9)$ & 0.0 \\
\hline Upper respiratory tract infection & $18.0(16.4)$ & $1.0(0.9)$ & 0.0 \\
\hline Rash & $18.0(16.4)$ & 0.0 & 0.0 \\
\hline Decreased appetite & $16.0(14.5)$ & 0.0 & 0.0 \\
\hline Neutropenia & $1.0(0.9)$ & $15.0(13.6)$ & 0.0 \\
\hline Vomiting & $15.0(13.6)$ & 0.0 & 0.0 \\
\hline Asthenia & $13.0(11.8)$ & $1.0(0.9)$ & 0.0 \\
\hline Back pain & $14.0(12.7)$ & 0.0 & 0.0 \\
\hline Constipation & $14.0(12.7)$ & 0.0 & \\
\hline Dyspnea & $11.0(10.0)$ & $3.0(2.7)$ & 0.0 \\
\hline Hypokalemia & $11.0(10.0)$ & $3.0(2.7)$ & 0.0 \\
\hline Insomnia & $14.0(12.7)$ & 0.0 & 0.0 \\
\hline Abdominal pain & $11.0(10.0)$ & $2.0(1.8)$ & 0.0 \\
\hline Platelet count decreased & $10.0(9.1)$ & $3.0(2.7)$ & 0.0 \\
\hline Pruritus & $12.0(10.9)$ & $1.0(0.9)$ & 0.0 \\
\hline Bronchitis & $12.0(10.9)$ & 0.0 & 0.0 \\
\hline Dizziness & $12.0(10.9)$ & 0.0 & 0.0 \\
\hline Chills & $11.0(10.0)$ & 0.0 & 0.0 \\
\hline Dry mouth & $11.0(10.0)$ & 0.0 & 0.0 \\
\hline Myalgia & $11.0(10.0)$ & 0.0 & 0.0 \\
\hline Pain in extremity & $10.0(9.1)$ & $1.0(0.9)$ & 0.0 \\
\hline Pneumonia & $3.0(2.7)$ & $7.0(6.4)$ & $1.0(0.9)$ \\
\hline Sinusitis & $11.0(10.0)$ & 0.0 & 0.0 \\
\hline
\end{tabular}


been demonstrated to repolarize $\mathrm{CD} 4^{+} \mathrm{T}$ cells from $\mathrm{Th} 2$ to $\mathrm{Th} 1$, possibly by inhibiting ITK, upon which Th2 cells are uniquely dependent for activation. ${ }^{14}$ This was confirmed by recent results in patients with CLL that suggested that ibrutinib may promote Th1 selection and switch to an adaptive response. ${ }^{28}$

Similarly, Th1-promoting cytokines, IFN- $\gamma$ and IL-12, were significantly increased only in patients who achieved a response, which suggests that response to ibrutinib in FL could be related to its T-cell immunomodulatory effects, which have also been observed in the post-allogeneic transplantation setting. ${ }^{14,29}$

Ibrutinib treatment also produced significant decreases in responders in MCP3 (also known as CCL7) and IP-10 (also known as CXCL10), which have been implicated in tumor development. ${ }^{30}$ These results, along with a clinical observation of pseudoprogression in some patients, suggest that the immunomodulatory effects of ibrutinib may be linked to a response to therapy. These hypothesisgenerating findings must be confirmed by analysis of tumor samples and explained in light of data that indicate that BTK inhibition may be effective in the treatment of graft-versus-host disease. ${ }^{25,31,32}$

This study provides critical insights into the differential biology of BTK inhibition in various B-cell malignancies and raises important questions about the broader effect of this strategy on the immunologic milieu of malignancy. The results of this study do not support ibrutinib monotherapy for patients with relapsed/ refractory FL; however, some patients experienced prolonged remission durations and symptom relief with no new safety signals. The relative clinical benefit of ibrutinib in FL will be further defined in ongoing phase III trials of chemoimmunotherapy with or without ibrutinib (ClinicalTrials.gov identifier: NCT01974440) in the relapsed/refractory setting and rituximab-ibrutinib versus rituximab monotherapy in treatment-naïve patients with FL (ClinicalTrials.gov identifier: NCT02947347). Additional biomarker studies may identify patients who may benefit from ibrutinib treatment, and the results of ongoing studies of combination therapies may identify effective treatment regimens. The effect of augmenting the potential immunomodulatory effect of ibrutinib is also being explored in combination with immune checkpoint inhibitors in patients with non-Hodgkin lymphoma (ClinicalTrials.gov identifier: NCT02950220 and NCT02332980).
These data provide the foundation for a better understanding of the biology and clinical role of BTK inhibition in B-cell malignancies.

\section{AUTHORS' DISCLOSURES OF POTENTIAL CONFLICTS OF INTEREST}

Disclosures provided by the authors are available with this article at jco.org.

\section{AUTHOR CONTRIBUTIONS}

Conception and design: Ajay K. Gopal, Stephen J. Schuster, Nathan H. Fowler, Georg Hess, Jing-Zhou Hou, Abdulraheem Yacoub, Michael Lill, Peter Martin, Umberto Vitolo, Wojciech Jurczak, James Morton, Dolores Caballero, Sanjay Deshpande, Gary J. Gartenberg, Shean-Sheng Wang, Michael Schaffer, Sriram Balasubramanian, Jessica Vermeulen, Bruce D. Cheson, Gilles Salles

Provision of study materials or patients: Ajay K. Gopal, Stephen J. Schuster, Nathan H. Fowler, Judith Trotman, Georg Hess, Jing-Zhou Hou, Abdulraheem Yacoub, Michael Lill, Peter Martin, Umberto Vitolo, Andrew Spencer, John Radford, Wojciech Jurczak, James Morton, Dolores Caballero, Sanjay Deshpande, Gary J. Gartenberg, Shean-Sheng Wang, Jessica Vermeulen, Bruce D. Cheson, Gilles Salles

Collection and assembly of data: Ajay K. Gopal, Stephen J. Schuster, Nathan H. Fowler, Judith Trotman, Georg Hess, Jing-Zhou Hou, Abdulraheem Yacoub, Michael Lill, Peter Martin, Umberto Vitolo, Andrew Spencer, John Radford, Wojciech Jurczak, James Morton, Dolores Caballero, Sanjay Deshpande, Gary J. Gartenberg, Shean-Sheng Wang, Rajendra N. Damle, Michael Schaffer, Sriram Balasubramanian, Jessica Vermeulen, Bruce D. Cheson, Gilles Salles

Data analysis and interpretation: Ajay K. Gopal, Stephen J. Schuster, Nathan H. Fowler, Judith Trotman, Georg Hess, Jing-Zhou Hou, Abdulraheem Yacoub, Michael Lill, Peter Martin, Umberto Vitolo, Andrew Spencer, John Radford, Wojciech Jurczak, James Morton, Dolores Caballero, Sanjay Deshpande, Gary J. Gartenberg, Shean-Sheng Wang, Rajendra N. Damle, Michael Schaffer, Sriram Balasubramanian, Jessica Vermeulen, Bruce D. Cheson, Gilles Salles

Manuscript writing: All authors

Final approval of manuscript: All authors

Accountable for all aspects of the work: All authors

\section{REFERENCES}

1. Al-Hamadani M, Habermann TM, Cerhan JR, et al: Non-Hodgkin lymphoma subtype distribution, geodemographic patterns, and survival in the US: A longitudinal analysis of the National Cancer Data Base from 1998 to 2011. Am J Hematol 90:790-795, 2015

2. Armitage JO, Weisenburger DD: New approach to classifying non-Hodgkin's lymphomas: Clinical features of the major histologic subtypes. Non-Hodgkin's Lymphoma Classification Project. J Clin Oncol 16:2780-2795, 1998

3. Dreyling M, Ghielmini M, Rule S, et al: Newly diagnosed and relapsed follicular lymphoma: ESMO Clinical Practice Guidelines for diagnosis, treatment and follow-up. Ann Oncol 27:v83-v90, 2016 (suppl 5)

4. Bachy E, Houot R, Morschhauser F, et al: Longterm follow up of the FL2000 study comparing CHVPinterferon to CHVP-interferon plus rituximab in follicular lymphoma. Haematologica 98:1107-1114, 2013
5. Casulo C, Nastoupil L, Fowler NH, et al: Unmet needs in the first-line treatment of follicular lymphoma. Ann Oncol 28:2094-2106, 2017

6. Cheah $\mathrm{CY}$, Fowler $\mathrm{NH}$, Wang ML: Breakthrough therapies in B-cell non-Hodgkin lymphoma. Ann Oncol 27:778-787, 2016

7. Janssen Biotech: Imbruvica prescribing information. https://wnw.imbruvica.com/docs/ibrariesprovider7/defaultdocument-library/prescribing-information.pdf

8. Janssen Pharmaceuticals: Imbruvica Summary of Product Characteristics. Beerse, Belguim, Janssen Pharmaceutica NV, 2017

9. Advani RH, Buggy JJ, Sharman JP, et al: Bruton tyrosine kinase inhibitor ibrutinib (PCl-32765) has significant activity in patients with relapsed/ refractory B-cell malignancies. J Clin Oncol 31: 88-94, 2013

10. Bartlett $N$, LaPlant $B$, Jing $Q$, et al: Ibrutinib monotherapy in relapsed/refractory follicular lymphoma (FL): Preliminary results of a phase 2 consortium (PC2) trial. Blood 124:800, 2014 (abstr)
11. Fowler N, Boyd T, Sharman J, et al: Long-term follow-up and analysis of dose groups with ibrutinib in relapsed follicular lymphoma. Blood 126:2706, 2015 (abstr)

12. Dave SS, Wright G, Tan B, et al: Prediction of survival in follicular lymphoma based on molecular features of tumor-infiltrating immune cells. N Engl J Med 351:2159-2169, 2004

13. Yang ZZ, Ansell SM: The tumor microenvironment in follicular lymphoma. Clin Adv Hematol Oncol 10:810-818, 2012

14. Dubovsky JA, Beckwith $K A$, Natarajan G, et al: Ibrutinib is an irreversible molecular inhibitor of ITK driving a Th1-selective pressure in T lymphocytes. Blood 122:2539-2549, 2013

15. Nishimura T, Nakui $M$, Sato $M$, et al: The critical role of Th1-dominant immunity in tumor immunology. Cancer Chemother Pharmacol 46: S52-S61, 2000 (suppl)

16. Cheson BD, Ansell S, Schwartz $L$, et al: Refinement of the Lugano Classification lymphoma 
response criteria in the era of immunomodulatory therapy. Blood 128:2489-2496, 2016

17. Cheson BD, Pfistner B, Juweid ME, et al: Revised response criteria for malignant lymphoma. J Clin Oncol 25:579-586, 2007

18. Solal-Céligny $P$, Roy $P$, Colombat $P$, et al: Follicular lymphoma international prognostic index. Blood 104:1258-1265, 2004

19. Byrd JC, Brown JR, O'Brien S, et al: Ibrutinib versus ofatumumab in previously treated chronic lymphoid leukemia. N Engl J Med 371:213-223, 2014

20. Burger JA, Tedeschi A, Barr PM, et al: Ibrutinib as initial therapy for patients with chronic lymphocytic leukemia. N Engl J Med 373:2425-2437, 2015

21. Dreyling $M$, Jurczak $W$, Jerkeman $M$, et al: Ibrutinib versus temsirolimus in patients with relapsed or refractory mantle-cell lymphoma: An international, randomised, open-label, phase 3 study. Lancet 387:770-778, 2016

22. Chanan-Khan $A$, Cramer $P$, Demirkan F, et al: Ibrutinib combined with bendamustine and rituximab compared with placebo, bendamustine, and rituximab for previously treated chronic lymphocytic leukaemia or small lymphocytic lymphoma (HELIOS): A randomised, double-blind, phase 3 study. Lancet Oncol 17: 200-211, 2016

23. Noy $A$, de Vos $S$, Thieblemont $C$, et al: Targeting Bruton tyrosine kinase with ibrutinib in relapsed/refractory marginal zone lymphoma. Blood 129:2224-2232, 2017

24. Myklebust JH, Brody J, Kohrt HE, et al: Distinct patterns of B-cell receptor signaling in non-Hodgkin lymphomas identified by single-cell profiling. Blood 129:759-770, 2017

25. Irish JM, Myklebust JH, Alizadeh AA, et al: Bcell signaling networks reveal a negative prognostic human lymphoma cell subset that emerges during tumor progression. Proc Natl Acad Sci USA 107: 12747-12754, 2010

26. Damle R, Schaffer M, Chaturvedi S, et al: Early changes in circulating T-cell immune profiles in patients with relapsed chronic lymphocytic leukemia/ small lymphocytic lymphoma: Data from the phase 3 , double-blind HELIOS trial. Blood 128:4397, 2016 (abstr)
27. Kondo K, Burger J, Michael K, et al: Ibrutinib can modulate the $T$ cell response in chronic lymphocytic leukemia by reducing PD1/PDL1 interactions. Blood 126:1737, 2015 (abstr)

28. Cubillos-Zapata $C$, Avendaño-Ortiz J, Córdoba $R$, et al: Ibrutinib as an antitumor immunomodulator in patients with refractory chronic lymphocytic leukemia. Oncolmmunology 5:e1242544, 2016

29. Ryan $C E$, Sahaf $B$, Logan $A C$, et al: Ibrutinib efficacy and tolerability in patients with relapsed chronic lymphocytic leukemia following allogeneic HCT. Blood 128:2899-2908, 2016

30. Binder M, O'Byrne MM, Maurer MJ, et al: Associations between elevated pre-treatment serum cytokines and peripheral blood cellular markers of immunosuppression in patients with lymphoma. Am J Hematol 92:752-758, 2017

31. Dubovsky JA, Flynn R, Du J, et al: Ibrutinib treatment ameliorates murine chronic graft-versushost disease. J Clin Invest 124:4867-4876, 2014

32. Miklos D, Cutler CS, Arora M, et al: Ibrutinib for chronic graft-versus-host disease after failure of prior therapy. Blood 130:2243-2250, 2017

\section{Affiliations}

Ajay K. Gopal, The University of Washington; Ajay K. Gopal, Fred Hutchinson Cancer Research Center, Seattle, WA; Stephen J. Schuster, Abramson Cancer Center of the University of Pennsylvania, Philadelphia; Jing-Zhou Hou, University of Pittsburgh Medical Center; Jing-Zhou Hou, University of Pittsburgh Cancer Institute, Pittsburgh; Rajendra N. Damle, Michael Schaffer, and Sriram Balasubramanian, Janssen Research \& Development, Spring House, PA; Nathan H. Fowler, The University of Texas MD Anderson Cancer Center, Houston, TX; Judith Trotman, Concord Hospital, University of Sydney, Sydney, New South Wales; Andrew Spencer, Alfred Hospital-Monash University, Melbourne, Victoria; James Morton, Haematology and Oncology Clinics of Australia, Milton, Queensland, Australia; Georg Hess, Johannes Gutenberg-University, Mainz, Germany; Abdulraheem Yacoub, Kansas University Medical Center, Kansas City, KS; Michael Lill, Cedars-Sinai Medical Center, Los Angeles, CA; Peter Martin, Weill Cornell Medical College, Cornell University, New York, NY; Umberto Vitolo, Azienda Ospedaliero Universitaria Città della Salute e della Scienza di Torino, Turin, Italy; John Radford, University of Manchester; John Radford, Christie National Health Service Foundation Trust, Manchester Academic Health Science Centre, Manchester, United Kingdom; Wojciech Jurczak, Jagiellonian University, Kraków, Poland; Dolores Caballero, Hospital Clínico Universitario, Salamanca, Spain; Sanjay Deshpande, Gary J. Gartenberg, and Shean-Sheng Wang, Janssen Research \& Development, Raritan, NJ; Jessica Vermeulen, Janssen Research \& Development, Leiden, the Netherlands; Bruce D. Cheson, Georgetown University Hospital, Washington, DC; and Gilles Salles, Hospices Civils de Lyon-Université de Lyon, Pierre-Bénite cedex, Lyon, France.

Supported by Janssen Research \& Development.

\section{Support}

\section{Prior Presentation}

Presented at the 58th American Society of Hematology Annual Meeting and Exposition, San Diego, CA, December 3-6, 2016, the 22nd Congress of the European Hematology Association, Madrid, Spain, June 22-25, 2017, and the International Conference on Malignant Lymphoma, Lugano, Switzerland, June 14-17, 2017. 


\section{AUTHORS' DISCLOSURES OF POTENTIAL CONFLICTS OF INTEREST}

Ibrutinib as Treatment for Patients With Relapsed/Refractory Follicular Lymphoma: Results From the Open-Label, Multicenter, Phase II DAWN Study

The following represents disclosure information provided by authors of this manuscript. All relationships are considered compensated. Relationships are self-held unless noted. I = Immediate Family Member, Inst = My Institution. Relationships may not relate to the subject matter of this manuscript. For more information about ASCO's conflict of interest policy, please refer to www.asco.org/rwc or ascopubs.org/jco/site/ifc.

\section{Ajay K. Gopal}

Consulting or Advisory Role: Seattle Genetics, Gilead Sciences, Janssen Pharmaceuticals, Brim, Aptevo

Research Funding: Merck (Inst), Janssen Pharmaceuticals (Inst), Spectrum (Inst), Takeda (Inst), Bristol-Myers Squibb (Inst), Pfizer (Inst) Seattle Genetics (Inst), Gilead Sciences (Inst)

\section{Stephen J. Schuster}

Honoraria: Celgene, DAVAOncology, Genentech, Gilead Sciences, Merck, Novartis, Pharmacyclics, Janssen Pharmaceuticals, Seattle Genetics Consulting or Advisory Role: Celgene, Pharmacyclics, Nordic Nanovector, Genentech, Gilead Sciences, Merck, Novartis, Janssen Pharmaceuticals, Seattle Genetics

Research Funding: Novartis (Inst), Janssen Research \& Development (Inst), Pharmacyclics (Inst), Celgene (Inst), Genentech (Inst), Merck (Inst), Seattle Genetics (Inst)

\section{Nathan H. Fowler}

Consulting or Advisory Role: Pharmacyclics, Janssen Pharmaceuticals Research Funding: Pharmacyclics (Inst), Janssen Pharmaceuticals (Inst)

\section{Judith Trotman}

Consulting or Advisory Role: Janssen Pharmaceuticals, Celgene, Takeda Research Funding: Janssen Pharmaceuticals (Inst), Genentech (Inst), BeiGene (Inst), Pharmacyclics (Inst), Celgene (Inst)

\section{Georg Hess}

Honoraria: Roche, Janssen Pharmaceuticals, Celgene, Novartis, CTI Biopharma

Consulting or Advisory Role: Roche, Janssen Pharmaceuticals, Celgene, Morphosys, Gilead Sciences, CTI Biopharma

Research Funding: Roche (Inst), Pfizer, Celgene, Mundipharma, CTI Biopharma

\section{Jing-Zhou Hou}

No relationship to disclose

\section{Abdulraheem Yacoub}

Consulting or Advisory Role: Seattle Genetics, Incyte

Speakers' Bureau: Incyte, Seattle Genetics, Novartis, CTI Biopharma

\section{Michael Lill}

No relationship to disclose

\section{Peter Martin}

Consulting or Advisory Role: Celgene, Janssen Pharmaceuticals, Gilead Sciences, Verastem, Genentech, Pharmacyclics, Acerta Pharma, AstraZeneca, Kite Pharma, Seattle Genetics, BaNot

\section{Umberto Vitolo}

Consulting or Advisory Role: Roche, Janssen Pharmaceuticals, Celgene Speakers' Bureau: Roche, Celgene, Takeda, Gilead Sciences, Janssen Pharmaceuticals Sandoz

Travel, Accommodations, Expenses: Roche, Janssen Pharmaceuticals, Takeda, Celgene, Gilead Sciences

\section{Andrew Spencer}

No relationship to disclose

\section{John Radford}

Stock or Other Ownership: AstraZeneca, GlaxoSmithKline

Honoraria: Takeda, Seattle Genetics, Novartis

Speakers' Bureau: Takeda, Seattle Genetics, Novartis

Research Funding: Takeda (Inst), Bristol-Myers Squibb, Seattle Genetics, Novartis

Wojciech Jurczak

Research Funding: Pharmacyclics, Janssen Pharmaceuticals

James Morton

No relationship to disclose

Dolores Caballero

No relationship to disclose

Sanjay Deshpande

Employment: Janssen Research \& Development

Stock or Other Ownership: Johnson \& Johnson

Gary J. Gartenberg

Employment: Janssen Research \& Development

Shean-Sheng Wang

Employment: Janssen Research \& Development

Stock or Other Ownership: Johnson \& Johnson

Rajendra N. Damle

Employment: Janssen Research \& Development

Michael Schaffer

Employment: Janssen Research \& Development

Stock or Other Ownership: Johnson \& Johnson

Sriram Balasubramanian

Employment: Janssen Research \& Development, AbbVie

Stock or Other Ownership: Janssen Research \& Development

Jessica Vermeulen

Employment: Janssen Research \& Development

Stock or Other Ownership: Johnson \& Johnson

Honoraria: Johnson \& Johnson

Bruce D. Cheson

Consulting or Advisory Role: Acerta, AbbVie, Pharmacyclics, Genentech Research Funding: Acerta (Inst), AbbVie (Inst), Pharmacyclics (Inst), Genentech (Inst), Gilead Sciences (Inst), TG Therapeutics (Inst)

Gilles Salles

Honoraria: Genentech, Amgen, Janssen Pharmaceuticals, Bristol-Myers Squibb, Celgene, Servier, Gilead Sciences, Novartis, Morphosys, Mundipharma, Merck

Consulting or Advisory Role: Genentech, Gilead Sciences, Janssen Pharmaceutical, Celgene, Novartis, Novimmune, Merck Amgen, Morphysis, Servier

Research Funding: Genentech (Inst)

Travel, Accommodations, Expenses: Genentech, Sanofi 


\section{Acknowledgment}

We thank the patients who participated in this trial and their families, as well as the global study investigators and study staff at each of the clinical sites. We also acknowledge members of the independent review committee and thank them for their contributions. Writing assistance was provided by Jill See of PAREXEL and was funded by Janssen Global services. 